\title{
Effects of sodium chloride on the growth parameters of Brassica campestris
}

\author{
Kainat $^{1 *}$, Muhammad Anwar Sajad ${ }^{1}$, Hassam Zafar ${ }^{1}$, Shafi Ahmad ${ }^{1}$, \\ Wasim Haider ${ }^{1}$, Mahnoor ${ }^{1}$ and Zaib-Un-Nisa ${ }^{2}$ \\ 1. Department of Botany, Islamia College (A Public Sector University) Peshawar, Peshawar, Khyber Pakhtunkhwa, \\ Pakistan \\ 2. Department of Botany, Women University Swabi, Khyber Pakhtunkhwa, Pakistan \\ *Corresponding author's email: kainatalikhan98@gmail.com \\ Citation \\ Kainat, Muhammad Anwar Sajad, Hassam Zafar, Shafi Ahmad, Wasim Haider, Mahnoor and Zaib-Un-Nisa. Effects \\ of sodium chloride on the growth parameters of Brassica campestris. Pure and Applied Biology. Vol. 10, Issue 4, \\ pp1369-1379. http://dx.doi.org/10.19045/bspab.2021.100142
}

\begin{tabular}{llll}
\hline \hline Received: 18/01/2021 & Revised: 06/04/2021 & Accepted: 10/04/2021 & Online First: 22/04/2021 \\
\hline
\end{tabular}

\section{Abstract}

The genus Brassica is an important agricultural and horticultural crop belongs to family Brassicaceae. Brassica species and varieties are commonly used for food include broccoli, cauliflower, cabbage, rutabaga, turnip and sometime used as production of canola oil and condiment mustard. Research work was conducted to investigate the effect of different concentrations of sodium chloride on the growth parameters of Brassica campestris. For this purpose, an experiment was carried out in triplicate in green house condition at the botanical garden of Islamia College Peshawar. The experimental design consisted of two major groups which were subdivided into each of four sub-groups. Each group pots were arranged in control and experimental soil (to which different concentration of $\mathrm{NaCl}$ were added). Group 1 was control (non-saline) and Exp-1, Exp-2 and Exp-3 were the groups to which $62.5 \mathrm{mM}, 125 \mathrm{mM}, 250 \mathrm{mM}$ sodium chloride were added respectively. Group 2 was control (non-saline) and Exp-1, Exp-2 and Exp-3 have concentrations $375 \mathrm{mM}, 500 \mathrm{mM}$ and $625 \mathrm{mM}$ respectively. Overall results showed that high and medium concentrations delay and suppressed the rate of germination, minimize the number of leaves, decrease shoot and root length while low concentration was not affected growth parameters. However, low concentration of $\mathrm{NaCl}$ showed no significant decrease in fresh weight, while $\mathrm{NaCl}$ medium concentration was decreased the fresh weight of selected plant, significantly as compare to high concentration. It is observed from current research work that B. campestris cannot tolerate high concentration of $\mathrm{NaCl}$ and damage under a high salt stress condition.

Keywords: Brassica compestries; Growth Parameters; NaCl; Salt Stress; Soil

\section{Introduction}

Salt stress is the agglomeration of excessive salt contents in the soil which eventually results in the inhibition of crop growth, agriculture productivity, and genetic potential and affects the plants such as ions toxicity, nutritional disorders, alternation of metabolic processes, oxidative stress, genotoxicity, reduction of the cell division, membrane disorganization. On global scale, salt stress is more dangerous with respect to other toxic substance, $20 \%$ cultivated land affected by soil salinity due to impoverished soaking of water and used brackish [1]. About $10-35 \%$ of the world's agricultural is effected by salinity in each year. Although 
avoid the water management practices, reclaim damaged land [2]. There is a high significant to better crop plants for salinity tolerance, but Brassica has a substantial to growth salt affected region. One of the most perspective is the improvement of salt sufferance of the cultivated species [3]. Salinity change the plant body of the wheat also disturb the metabolism, physiologic al and enzymatic process of the wheat plant [4]. Two basic stresses, osmotic and ionic stresses have been change the plants morphology as well as physiology. Osmotic stress result in inhibition of water uptake, cell expansion while ionic stress develops in excessive sodium cause leaf morality, chlorosis and necrosis [5]. Two basic approaches have been used, first technological approach for reclamation, drainage and irrigation of water, second one biological strategies which focus on development of high qualities of plants which tolerate high level of salts [6]. Growth analysis is one of the most popular treat to study the plant response toward an environmental stress. Genetically and physiologically salt tolerance is difficult among the verities of plants in halophytes and less tolerance plants [7]. Salinity affects photosynthesis by reducing the availability of $\mathrm{CO}_{2}$, as a result of diffusion limitations and reduces the photosynthetic pigments. Excessive salt content decreasing stomatal and mesophyll conductance to $\mathrm{CO}_{2}$, which can affect light absorbance [8]. Salinity is one of the major abiotic stresses around the world and causes greater losses to crop plants. The issue of salinity becomes more dangerous when plants are exposed to $\mathrm{Cd}$ stress [9]. Dominancy of the Brassica vegetables such as Chinese cabbage, broccoli, cabbage, cauliflower in terms of their nutrient quality for human diet and refined food has increased significant variation was detailed in seed germination between canola cultivars grown under salinity environment. Salinity tolerance is also reported in species of canola $B$. napus and $B$. campestris [10]. Due to excessive salt contents soils result minimize crop loss, so scientists have searched those plant which have the potential to grow in high concentration of salt [11]. Saline soils expose plants to osmotic stress, due to which reactive oxygen species (ROS) product in large amounts that followed by oxidative damages, e.g., the destruction of proteins, lipids, pigments, and DNA [12]. Furthermore, salinity affects membrane permeability, enzyme kinetics chlorophyll, photosynthesis, stomatal conductance, concentration of ions and metabolite and nutrient uptake through competitive interaction by affecting the ion selectivity of membranes thus resulting reducing plant growth and development [13]. In several regions of the world, salinity stress may occur due to $\mathrm{Na}^{+}$and $\mathrm{Cl}^{-}$which may be greater than those of other salts present in the soil or water [14]. Salinity showed significant reduction at different stage of the species of Ocimum basilicum, petroselinum hortense, sweet marjoram and thymus maroccanus [15, 16].

\section{Materials and Methods Selection of plant}

The Brassica campestris was selected for the experimental work which is an annual herb grow up to $1 \mathrm{~m}$ or higher.

\section{Collection of plant seeds}

The seeds of Brassica campestris were purchased from the Board Bazar Peshawar, Khyber Pakhtunkhwa, Pakistan. The seeds were cleaned by the same procedure followed by Nisa et al. [17] Nisa et al. [18], Nisa et al. [19], Nisa et al. [20], Nisa et al. [21], Malik et al. [22], Nisa et al. [23], and Gul et al. [24].

\section{Experimental design}

Total 24 pots were used in each experiment. These 24 pots were divided into two groups each groups consisted of 12 pots which were arranged on the basis of different concentrations of salt stress used in the experiment. Each experiment was conducted 
in triplicate in the greenhouse condition at the botanical garden, Islamia College Peshawar. The experimental design consisted of two major group 1 and group 2, each of them were divided into four minor groups which were arranged in sequences line. The main groups $(1,2)$ were Control, and experiment 1, experiment 2, experiment 3 were the subgroups.

\section{Seed sowing}

240 seeds were used in research work. 120 seeds were sown in each major group. Ten seeds of B. campestris were sown in each pot of allgroups.

Concentration of salt $(\mathrm{NaCl})$ used in experiment

Different concentrations of sodium chloride stress were used in the experimental groups. No salt $(\mathrm{NaCl})$ was used in control groups (Control 1), while $62.2 \mathrm{mM}, 125 \mathrm{mM}, 250$ $\mathrm{mM}$ of $\mathrm{NaCl}$ was added in solution form to each one pot of rest of the groups i.e. Expe1, Exp2 and Exp3 respectively. No salt was used in control group (Control 2) while 375 $\mathrm{mM}, 500 \mathrm{mM}$ and $625 \mathrm{mM}$ of $\mathrm{NaCl}$ was added in solution form to each pot of rest of subgroups i.e. Exp 1, Exp 2 and Exp3 respectively.

\section{Procedure for calculation}

The procedure followed by Nisa et al. [17] Nisa et al. [18], Nisa et al. [19], Nisa et al. [20], Nisa et al. [21], Malik et al. [22], Nisa et al. [23], Gul et al. [24] was used for the solution preparation and taking replicates. 1 Molar = weight in gram $/ 1$ litter of water $1 \mathrm{M}=1000 \mathrm{mM}$ solution

So, 1 Molar solution of $\mathrm{NaCl}=1000 \mathrm{mM}$ solution of $\mathrm{NaCl}=58.5 \mathrm{~g} \mathrm{NaCl} / 1000 \mathrm{ml}$ Using the above formula for these three milli Molar solution were taken,

For $62.2 \mathrm{mM}=3.65 \mathrm{~g} \mathrm{NaCl}$ was dissolved in $1000 \mathrm{ml}$ of distilled water, repeated this procedure for three time and added these solutions in each pot of the experimental group 1 (major group 1).
For $125 \mathrm{mM}=7.31 \mathrm{~g} \mathrm{NaCl}$ was dissolved in $1000 \mathrm{ml}$ of distilled water, repeated this procedure for three time and added these solutions in each pot of the experimental group 2 (major group 1).

For $250 \mathrm{mM}=14.62 \mathrm{~g} \mathrm{NaCl}$ was dissolved in $1000 \mathrm{ml}$ of distilled water, repeated this procedure for three time and added these solutions in each pot of the experimental group 3 (major group 1).

For $375 \mathrm{mM}=21.93 \mathrm{~g} \mathrm{NaCl}$ was dissolved in $1000 \mathrm{ml}$ of distilled water, repeated this procedure for three time and added these solutions in each pot of the experimental group 1(major group 2).

For $500 \mathrm{mM}=29.25 \mathrm{~g} \mathrm{NaCl}$ was dissolved in $1000 \mathrm{ml}$ of distilled water, repeated this procedure for three time and added these solutions in each pot of experimental group 2 (major group 2).

For $625 \mathrm{mM}=36.56 \mathrm{~g} \mathrm{NaCl}$ was dissolved in $1000 \mathrm{ml}$ of distilled water, repeated this procedure for three time and added these solutions in each pot of experimental group 3 (major group 2).

Effect of $\mathrm{NaCl}$ on the rate of seed germination

The seeds of Brassica plant were grown on 27 October, 2019 and give solution of $\mathrm{NaCl}$ stress to the experimental groups. After sowing the seeds, the data (rate of seed germination) was recorded with the interval of three or four days. There was a clear difference in the rate of seed germination in control group and those which were treated with sodium chloride stress.

\section{Effect of $\mathrm{NaCl}$ on the plant length}

The plant length of both control and treated groups $(\mathrm{NaCl})$ were measured in centimeter as taken by Nisa et al. $(2020,2016)$. The plant length was considered from root to apex of the plant.

\section{Effect of $\mathrm{NaCl}$ on the number of leaves}

The numbers of leaves were counted in the plant grown in control group and those which 
were treated with different concentration of sodium chloride stress.

\section{Effect of $\mathrm{NaCl}$ on the Fresh Weight}

When the Brassica plant was reached to maturation stage then were harvested. Measured the fresh weight of Brassica plant was determined in gram ( $\mathrm{g}$ ) by using digital balance and recorded the data in control group and experimental groups.

\section{Results}

The experiment was conducted in the Botanical Garden Department of Botany Islamia College, Peshawar to find out the effect of sodium chloride on the various growth parameter of $B$. campestris. The experimental period continued for about one month from seed sowing up to the maturity of the plants. During this period data regarding seed germination and growth were recorded. The main growth parameters of the selected plant in relation of the effects of salinity studied in the course of this research work are:

\section{Effect of $\mathrm{NaCl}$ on the seed germination}

The effect of used six different concentrations of sodium chloride stress on the seed germination. These six different concentrations of sodium chloride stress comprised into two major group no 1 and group No. 2. Each of them three different concentrations given to each one experimental groups. Group 2, (375 mM/ $21.93 \mathrm{~g}, 500 \mathrm{mM} / 29.25 \mathrm{~g}$ and $625 \mathrm{mM} /$ $36.56 \mathrm{~g}$ ) the effect of used three different concentrations of sodium chloride stress on the rate of seed germination was determined. After a few days the data recorded about germination and seedling growth were exhibited in control group and treated (experimental groups) with different concentrations of sodium chloride stress as shown in the (Fig. 1). Error bar shows that standard deviation which was found statistically significant. Maximum reduction in seed germination was observed at a high concentration of sodium chloride stress on the soil (Exp 3) followed by (Exp 2) and (Exp 1) while maximum germination was found in untreated group (control group). Overall statistically significant difference was found in the rate of germination in the seeds grown in control and experimental groups using one-way ANOVA (at $\mathrm{P}<0.05$ and $\mathrm{P}$ value summary of $* * * *)$.

The results of group 1 which indicate the effect of three different concentrations, 62.2 $\mathrm{mM} / 3.65 \mathrm{~g}, \quad 125 \mathrm{mM} / 7.31 \mathrm{~g}$ and $250 \mathrm{mM} / 14.62 \mathrm{~g}$ of sodium chloride is shown in (Fig. 2) on the rate of seed germination. Error bar shows that standard deviation which was found statistically significant. Maximum reduction in seed germination was found at a high concentration of sodium chloride (Exp3) followed by $(\operatorname{Exp} 2)$ and (Exp1) with respect to non-salinity (control group). Maximum growth of seed germination was observed in control group with respect to experimental groups. Overall statistically significant different was found in rate of seed germination in the soil in control and treated groups (Experimental groups) using one-way ANOVA (at $p$ value $<0.05$ and $\mathrm{p}$ value summary of $* * *$ )

\section{Effect of $\mathrm{NaCl}$ on number of leave}

After maturation of plants were harvested from groups of each pot and counted the number of leaves of each plant. Group 2, showed different data regarding the number of leave in treated (experimental group) and untreated group (control group) as shown in (Fig. 3). Standard deviations were found statistically significant. Maximum reduction in number of leaves was observed at a high concentration of sodium chloride (Exp3) followed by (Exp1) and slightly maximum number of leaves in (Exp2) with respect to other experimental groups. While maximum number of leaves was observed in untreated (control group). Overall statistically significant difference was found in number of leaves in control group and treated (experimental groups) using one-way 
ANOVA (at $\mathrm{P}$ value $<0.05$ and $\mathrm{P}$ value summary $* * * *)$.

Group no 1, (Fig. 4) shows statistically significant results. Maximum reduction in number of leaves was found at a high concentrations of sodium chloride (Exp3) followed by (Exp2) and (Exp1) while maximum number of leaves the in saline soil was observed in control group compared to experimental groups. Overall statistically significant difference was observed in control and experimental groups using one-way ANOVA (at $\mathrm{P}$ value $<0.05$ and $\mathrm{P}$ value summary $* *)$.

\section{Effect of $\mathrm{NaCl}$ on plant length}

At the time of harvesting, selected ten plants from each pots of each one groups. Group 1, which indicate the effect of three different concentrations of sodium chloride i.e 375 $\mathrm{mM} / 21.93 \mathrm{~g}, 500 \mathrm{mM} / 29.25 \mathrm{~g}$ and $625 \mathrm{mM} /$ $36.56 \mathrm{~g}$ is shown in (Fig. 5). Maximum reduction in plant length was observed at a high concentrations of sodium chloride stress: the soil Exp 3 followed by Exp2 and Exp1 while maximum elongation of plant was found in non-saline soil. Overall statistically significant difference was found in untreated (control group) and treated (Experimental groups) using one-way ANOVA (at $\mathrm{P}$ value $<0.05$ and $\mathrm{P}$ value summary $* * * *)$.

The (Fig. 6) shows the effect of three different concentrations of sodium chloride stress (group 1). Maximum reduction in plant elongation was observed at high concentrations of sodium chloride stress in saline soil Exp3, Exp2 and followed by Exp1 while maximum plant elongation was found in control group. Overall statistically significant differences were found in control and experimental groups. One-way ANOVA was used for statistical analysis ( $\mathrm{P}$ value $<0.05$ and $\mathrm{P}$ value summary *).

\section{Effect of $\mathrm{NaCl}$ on fresh weight of plant}

Group 2, (the effect of three different concentration of sodium chloride stress i.e
$375 \mathrm{mM} / 21.93 \mathrm{~g}, \quad 500 \mathrm{mM} / 29.25 \mathrm{~g} \quad$ and $625 \mathrm{mM} / 36.56 \mathrm{~g}$ ) is shown in (Fig. 7). Maximum reduction in fresh weight of plant was observed at high concentrations of sodium chloride stress in Exp 3 followed by Exp1 and Exp2 while maximum fresh weight of plant was found in non-saline soil. Overall statistically significant difference was found in non-saline (control) and saline soil (experimental groups) using one-way ANOVA (at $\mathrm{P}$ value $<0.05$ and $\mathrm{P}$ value summary $* * * *)$.

The results indicated by group 1 (the effect of three different concentrations of sodium chloride stress $62.2 \mathrm{mM}, 125 \mathrm{mM}$ and 250 $\mathrm{mM}$ ) are presented in (Fig. 8). Maximum reduction in fresh weight of plant was observed at high concentrations of sodium chloride stress in Exp2 followed by Exp3 while maximum fresh weight of plant was found in Exp1 and non-saline soil (control group). Overall statistically significant difference was found in control and experimental groups 1 using one-way ANOVA ( $\mathrm{P}$ value $<0.05$ and $\mathrm{P}$ value summary $*)$.

\section{Discussion}

The effects of sodium chloride $(\mathrm{NaCl})$ on the rate of seed germination of selected reēsearch plant are presented in (Fig. 1-8). Results showed that increased in concentration of sodium chloride declined the rate of seed germination. However, (b) lower concentration of $\mathrm{NaCl}$ has less effect on seed germination. Our results are in agreement with the findings of Midaoui et al. [25], who studied the effect of $\mathrm{NaCl}$ on sunflower germination (Helianthus annuus), the seed of three sunflower genotypes (Oro9, Flamme and Albena) were germinated in petri dishes placed in an incubator maintained at $28^{\circ} \mathrm{C}$. Six $\mathrm{NaCl}$ concentrations $(0,50,75,100,125$ and $175 \mathrm{mM}$ ) were used to moisten seeds. Results showed a decline in seed germination of the three genotypes as $\mathrm{NaCl}$ concentration was increased in the medium. After six days 
of incubation, Significant differences were observed between control and treatments. Similar experiment was also conducted by Chachar et al. [26], they studied the effect of $\mathrm{NaCl}$ on seed germination and seedling root growth of cotton (Gossypium hirsutum L). In order to provide different degree of slat stress, cotton seeds were exposed to increasing salinity levels, $0 \mathrm{~mm}, 50 \mathrm{~mm}$, $100 \mathrm{~mm}, 150 \mathrm{~mm}$ and $200 \mathrm{~mm}$. It was reported that seed germination was only slightly affected by an increase in salinity (in most cases the differences between treatment were non-significant). So it is evident that from the (Fig. 1) that high level of $\mathrm{NaCl}$ solution slightly affect and delayed the rate of germination therefore result findings presented by Zheng et al. [27], are in agreement with our findings. Salinity causes the inhibition on the plant growth due to specific ions toxicity. Salinity stress caused a significant increase in $\mathrm{Na}^{+}$while decreases in $\mathrm{K}^{+}$, as results $\mathrm{K}^{+} / \mathrm{Na}^{+}$ratio is high. The excessive $\mathrm{K}^{+} / \mathrm{Na}^{+}$ratio was harm full to the growth parameters of wheat plants. Our finding is similar to the results of Amira et al. [28]. Results showed that the increased in concentration of $\mathrm{NaCl}$ caused the maximum reduction in leaves number while low concentration not significantly cause decrease in number of leaves of selected plant. Sozharajan and Natarajan [29], also reported the effect of salt stress on plant growth and metabolism of bean plant (Vicia faba (L.) No significant effect was observed in the number of leaves with low concentration, while a decrease was noticed, with higher concentrations. Furthermore, results showed that the increased concentration of sodium chloride caused significant reduction in plant shoot and root elongation. Similar result was conducted by Tuncturk et al. [30]. He demonstrated that the length of maize observed from germination of the maize seeds under salinity in laboratory condition, after 14 days observed the data of maize which is significantly reduced the length under salt treatment. Root length also decreased with increase in level of $\mathrm{NaCl}$. The effects of sodium chloride on the fresh weight of Brassica compestries showed that increased in concentration of sodium chloride decreased the fresh weight. But to smaller extent $\mathrm{NaCl}$ promote the fresh weight of Brassica with respect to high concentration of salinity. Similar experiment was conducted by Khan et al. [31] who worked on the effect of salinity stress on fresh weight and nutrient composition of some canola (Brassica napus L.) cultivars. For the 12 canola genotypes used in the salt treatments, the first marked symptomatic effect of toxic level $\mathrm{NaCl}$ for $150 \mathrm{~mm}$ dosage was reduction in the green parts weight and inhibition on the plant growth. According to our results, plant fresh weight was influenced significantly by the salt stress $(\mathrm{P}<0.01)$ while low and higher concentration not significantly decreased the fresh weight of plant, but medium concentration $(125 \mathrm{~mm})$ effect the fresh weight. These findings are not matched with the results of Khan et al. [31]. However, our findings similar to the results of Khan et al. [31] that dry weight of the rice plant are significantly reduce at a high concentration of sodium chloride. 


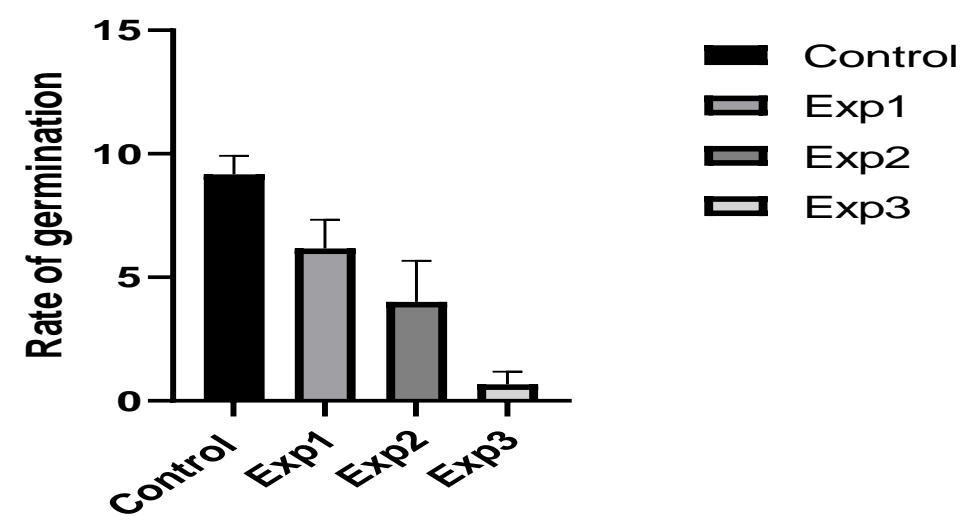

Growth of brassica plant in control and NaCl treated soil

Figure 1. Effect of different concentrations of $\mathrm{NaCl}$ on rate of seed germination of Brassica campestris

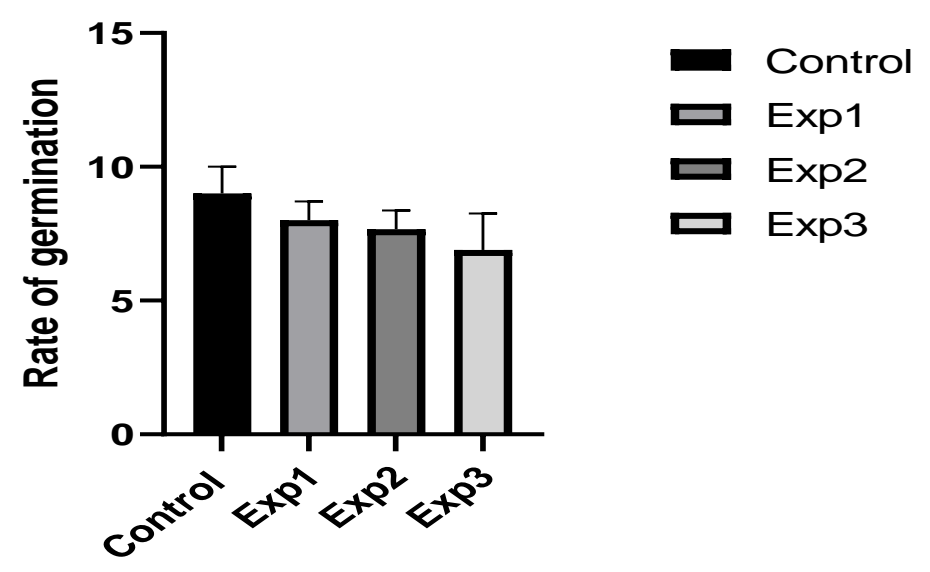

Growth of brassica plant in control and NaCl treated soil

Figure 2. Effect of different concentration of $\mathrm{NaCl}$ on rate of germination of Brassica campestris

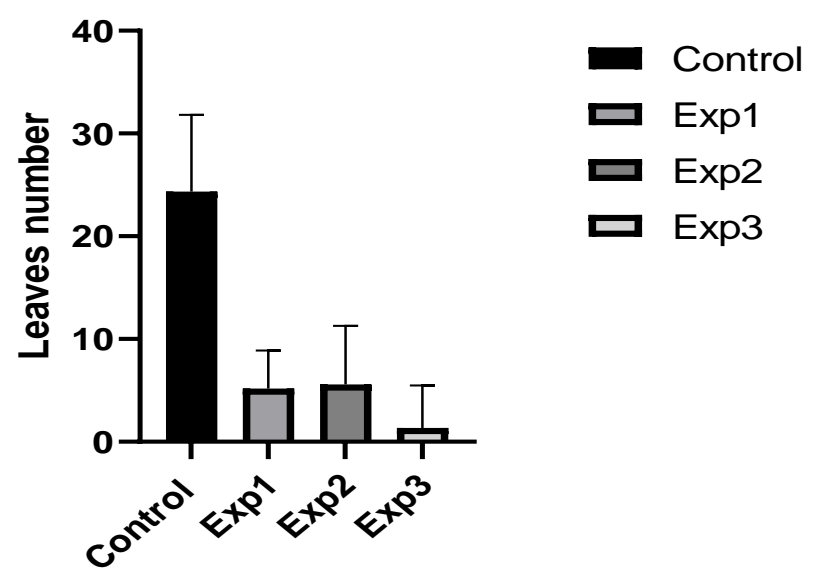

Growth of brassica plant in control and $\mathrm{NaCl}$ treated soil

Figure 3. Effect of different concentration of $\mathrm{NaCl}$ on number of leave of Brassica comprestis 


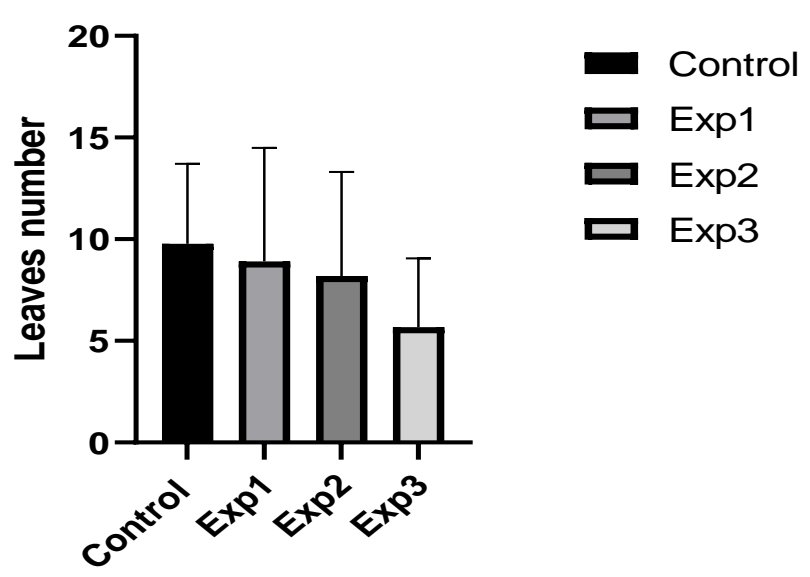

Growth of brassica plant in control and $\mathrm{NaCl}$ treated soil

Figure 4. Effect of different concentrations of $\mathrm{NaCl}$ on number of leave of Brassica campestris Figure 5. Effect of different concentration of $\mathrm{NaCl}$ on length of Brassica campestris

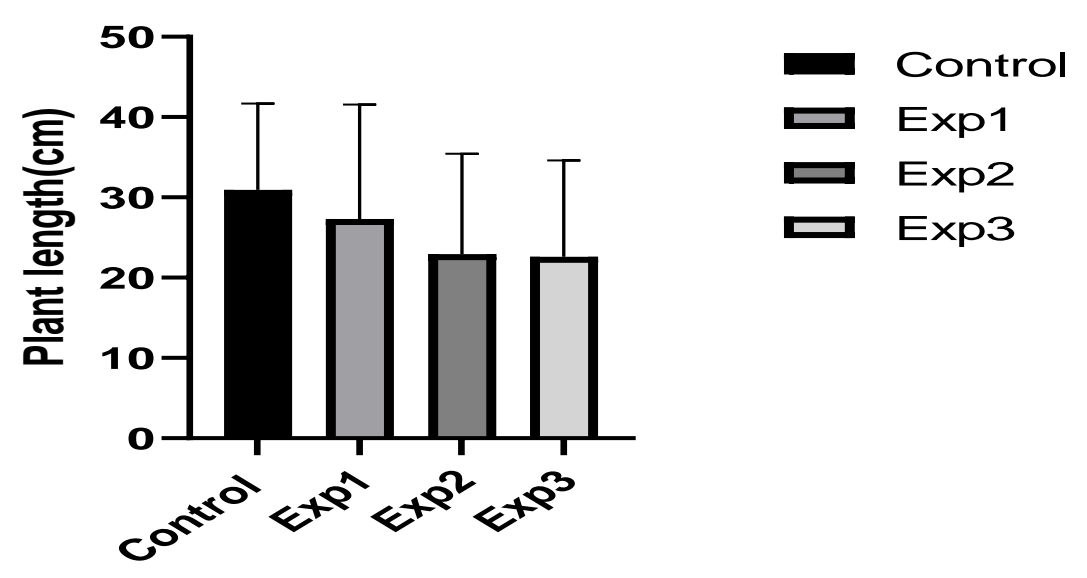

Growth of brassica plant in control and NaCl treated soil

Figure 6. Effect of different concentrations of $\mathrm{NaCl}$ on the length of Brassica campestris

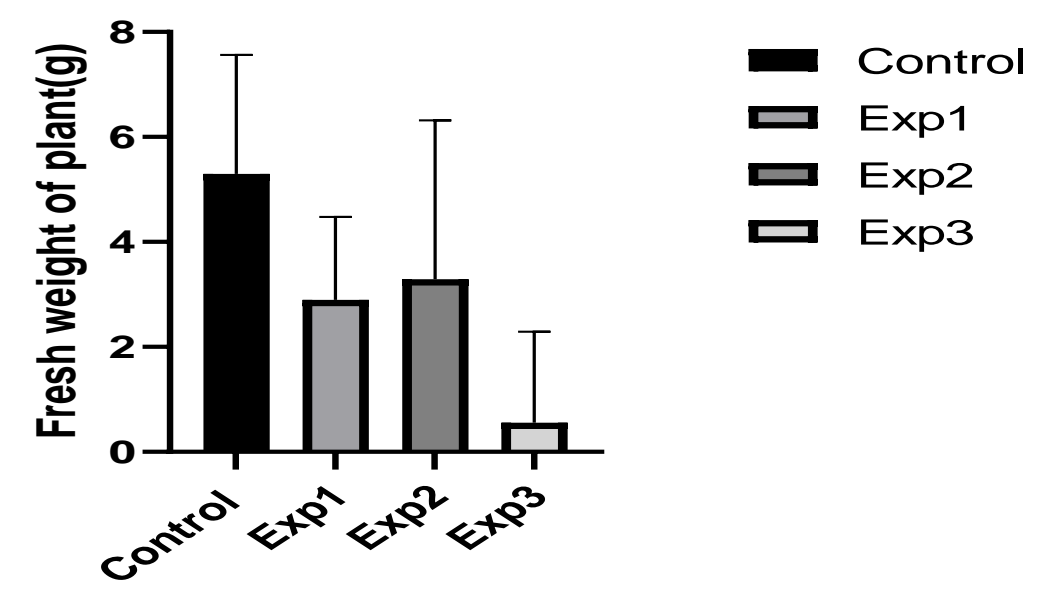

Growth of brassica plant in control and NaCl treated soil 
Figure 7. Effect of different concentration on fresh weight of Brassica campestris

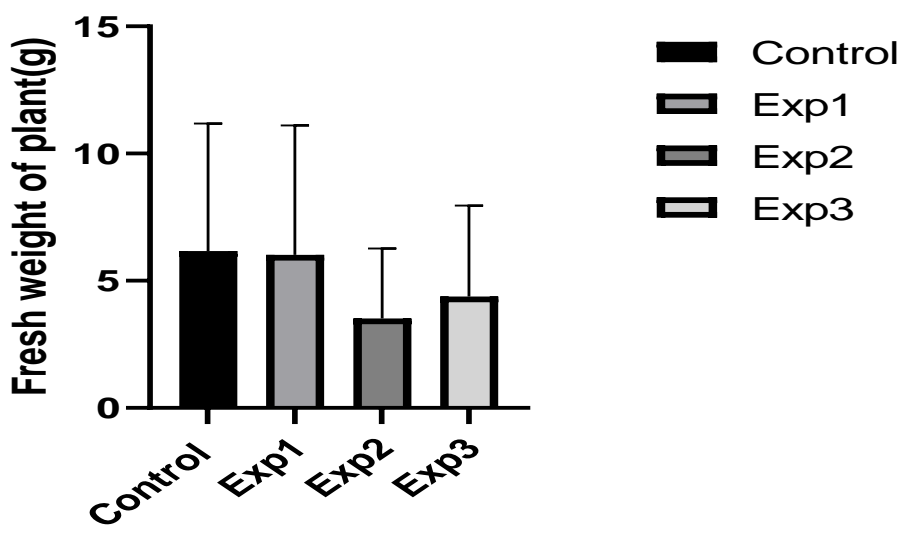

Growth of brassica plant in control and NaCl treated soil

Figure 8. Effect of different concentrations of $\mathrm{NaCl}$ on fresh weight of Brassica campestris

\section{Conclusion}

Based on the current research work It is concluded that high concentration of $\mathrm{NaCl}$ solution decreased the rate of germination in experimental groups than control group, but in the experimental groups rate of germination was not found significantly different, very high concentration of $\mathrm{NaCl}$ solution effect the number of leaves, plant length between experimental groups than low and medium concentration of $\mathrm{NaCl}$ as compared to the control group (no stress). $\mathrm{NaCl}$ affects the length of shoot and root of a plant, fresh and dry weight of the plant in experimental groups than control group. However low (62.5mM and $125 \mathrm{mM})$ concentration of $\mathrm{NaCl}$ was not significantly reduction in the height of plant as compared to high $(250 \mathrm{mM}, 375 \mathrm{mM}, 500 \mathrm{mM}$ and $625 \mathrm{mM}$ ) concentration and $\mathrm{NaCl}$ affects the fresh weight of the plant in experimental groups with respect to control group. It is concluded that high content of sodium chloride in soil or water caused significantly reduction in germination and growth parameters of Brassica compestries.

\section{Authors' contributions}

Conceived and designed the experiments: MA Sajad \& S Ahmad, Performed the experiments: Kainat, Analyzed the data: MA
Sajad \& Kainat, Contributed materials/ analysis/ tools: Kainat, H Zafar, S Ahmad, W Haider, Mahnoor \& MA Sajad, Wrote the paper: Kainat, ZU Nisa \& MA Sajad.

\section{Acknowledgments}

The research was conducted in the laboratory Department of of Botany, Islamia College Peshawar, and Khyber Pakhtunkhwa, Pakistan. The current research was especially supported by my respected supervisor, Dr. Muhammad Anwar Sajad and my research mate Shafi Ahmad and Wasim Haider.

\section{References}

1. Aslam R, Bostan N, Amen NE, Maria M \& Safdar W (2011). A critical review on halophytes: Salt tolerant plants. J of Med Plants Res (33): 7108-7118

2. Nawaz K, Hussain K, Majeed A, Khan F, Afghan S \& Ali K (2010). Fatality of salt stress to plants: Morphological physiological and biochemical aspects. Afri J of Biotechnol 9(34): 5475-5480.

3. Wani AS, Ahmad A, Hayat S \& Fariduddin Q (2013). Salt-induced modulation in growth, photosynthesis and antioxidant system in two varieties of Brassica juncea. Saudi J of Biol Sci 20: 183-193.

4. Ali S, Ali U, Khan WM, Ali K, Khan MS \& Shuaib M (2017). Effect of salt stress 
on the biochemical characteristics of selected wheat varieties. Pure Appl Biol 6(2): 691-700

5. Kainat \& Sajad MA (2020). Effects of sodium chloride on the growth parameter of canola plant. Pure Appl Biol 10(2): 492-502

6. Jamil A, Riaz S, Ashraf M \& Foolad MR (2011). Gene Expression Profiling of Plants under Salt Stress. Crit Rev in Plant Sci 30: 435-458

7. Mane AV, Karadge BA \& Samant JS (2011). Salt stress induced alteration in growth characteristics of a grass Pennisetum alopecuroides. $J$ Environ Biol 32: 753-758

8. Machado RMA \& Serralheiro RP (2017). Soil Salinity: Effect on Vegetable Crop Growth.Management Practices to Prevent and Mitigate Soil Salinization. horticulturae. pp. 3(30)

9. Raziuddin, Farhatullah, Hassan G, Akmal M, Shah SS, Mohhammad F, Shafi M, Bakht J \& Zhou W (2011). Effects of Candium and Salinity on growth and Photosynthesis Parameters of Brassica Species. Pak J Bot 43(1): 333-340.

10. Jamil M, Lee CC, Rehman SU, Lee DB, Ashraf M \& Rha ES (2005). Salinity $(\mathrm{NaCl})$ tolerance of Brassica species at germination and early seedling growth: Elec J of Environ, Agric, Food and Chem 4(4): 970-976.

11. Evelin H, Kapoor R \& Giri B (2009). Arbuscular mycorrhizal fungi in alleviation of salt stress: a review. Ann of Bot 104(7): 1263-1280

12. Gharelo RS \& Noparvar PM (2018). Molecular response of canola to salt stress: insights on tolerance mechanisms. Peer J 6:e4822 https://doi.org/10.7717/peerj.4822

13. Meena SK, Gupta NK, Gupta S, Khandelwal SK, Sastry EVD. Effect of sodium chloride on the growth and gas exchange of young Ziziphus seedling rootstocks. The J of Hortic Sci and Biotechnol 78(4): 45-54.
14. Khan WM, Khan MS, Karim S, Umar N \& Ali S (2016). Effect of salt stress on some morphological and biochemical characteristics of sunflower (Samsung600). Pure Appl Biol 5(3): 653-663.

15. Delgado IC \& Sanchez-Raya AJ (2007). Effects of Sodium Chloride and Mineral Nutrients on Initial Stages of Development of Sunflower Life. Commu in Soil Sci and Plant Anal 38: 2013-2027.

16. Aghae K \& Komatsu S (2013). Crop and medicinal plants protemics in response to salt stress: Fron in Plant Sci 4(8): 1-10.

17. Nisa ZU, Jan S \& Shah SH (2016). Standardization of Protocol for the Surface Sterilization and Callus Induction of Saussurea lappa: An Endangered Medicinal plant. Inter $J$ Biosci 9(1): 324-330.

18. ZU Nisa, Jan S, Sajad MA, Shah SH, Farooq G \& Ali H (2018). Micropropagation through apical shoot explants and morphogenic potential of different explants of Saussurea lappa: An endangered medicinal plant. Pure Appl Biol 8(1): 585-592.

19. Nisa ZU, Jan S, Shah SH, Farooq G, Sajad MA \& Khan MAS (2019). Assessment of the callus induction, relative growth rate, proline and sugar in Saussrea lappa C.B. Clarke. Pure Appl Biol 8(1): 838-846.

20. Nisa ZU, Shah SH, Farooq G, Sajad MA \& Khan MAS (2019). Identification, quantification and comparative assessment of costunolide in wild, cultivated and in vitro callus culture of Saussurea lappa by HPLC technique. Pure Appl Biol 8(1): 910-919.

21. Nisa ZU, Shah SH, Farooq G, Sajad MA \& Khan MAS (2019). Distribution and comparison of major selected elements in root of wild plant, root derived calli and various anatomical parts of cultivated Saussurea lappa: An endangered 
medicinal plant. Pure Appl Biol 8(2): 1478-1486.

22. Malik S, Khan MS, Sajad MA, Barkatullah, Saddiq G, Nisa ZU, Shah M \& Aziz N (2019). Evaluation of antibacterial potential of the leaves, flowers and bulbs of Allium neapolitanum cirillo. Pure Appl Biol 8(3): 2076-2086.

23. Nisa ZU, Shah AH, Shah SH, Farooq G, Sajad MA \& Khan MAS (2020). Effects of natural growth regulators on micropropagation of potatoes. Pure Appl Biol 9(2): 1442-1459.

24. Gul H, Nisa ZU, Jabeen A, Maryam \& Sajad MA (2020). An evaluation of phytochemical screening of Lantana camara Linn. (An invasive plant species of Pakistan). Pure Appl Biol 9(3): 18561863.

25. Midaoui M, Mohamed B \& Ahmed T (2002). Effect of sodium chloride on sunflower (Helianthus annuus L.) seed germination. Helia 25(37): 51-58

26. Chachar QI, Solangi AG \& Verhoef A (2008). Influence of sodium chloride on seed germination and seedling root growth of cotton (Gossypium hirsutum L.). Pak J Bot 40(1): 183-197.
27. Zheng Y, Jia A, Ning T, Xu J, Li Z \& Jiang G (2008). Potassium nitrate application alleviates sodium chloride stress in winter wheat cultivars differing in salt tolerance: J of Plant Physiol 165: 1455-1465.

28. Amira MS \& Qados A (2011). Effect of salt stress on plant growth and metabolism of bean plant Vicia faba (L.). $J$ of the Saudi Soc of Agric Sci 10: 7-15.

29. Sozharajan R \& Natarajan S (2014). Germination and seedling growth of zea mays L. under different levels of sodium chloride stress: Inter Letters of Nat Sci 7: 5-15.

30. Tuncturk M, Tuncturk R, Yildirim B \& Ciftci V (2011). Effect of salinity stress on plant fresh weight and nutrient composition of some canola (Brassica napus L.) cultivars. Afri J of Biotechnol 10(10): 1827-1832.

31. Khan MSA, Hamid A \& Karim MA (1997). Effect of Sodium Chloride on Growth, Photosynthesis and Mineral Ions Accumulation of Different Types of Rice (Oryza sativa L.). Agron \& Crop Sci 179: 163-169. 